\title{
Analisis Faktor Internal dan Eksternal pada Unit Pengolahan Teh Rakyat Kelompok Tani Barokah, Bandung
}

\section{(Analysis of Internal and External Factors on Tea Smallholder Processing Unit in Barokah Farmer Group, Bandung)}

\author{
Siti Utami Tammah ${ }^{1{ }^{*}}$, Lucyana Trimo ${ }^{1)}$ \\ ${ }^{1)}$ Program Studi Agribisnis Universitas Padjadjaran Jl. Raya Bandung-Sumedang Km. 21, \\ Jatinangor, Kabupaten Sumedang, Jawa Barat, Kode Pos 45363 \\ E-mail:tami.tammah@gmail.com
}

\begin{abstract}
The tea plantation area in Indonesia is still dominated by tea smallholder estate of 45,17\%. This is accompanied also by the growing number of tea agroindustry which increased by 0,83\% based on data from the ministry of industry period 2007 to 2013. One of the tea agroindustry that still survive is tea smallholder processing unit of Barokah Farmer Group in Lebak Muncang Village, District Ciwidey Regency Bandung. This study aims to analyze the internal and external factors of the tea smallholder processing units of Barokah Farmer Group. The technique used in this research is case study with the informants include the management of the in tea smallholder processing units in Barokah Farmer Group, the government agency of Bandung Plantation Office. The technique of data collection is done by observation, in-depth interview and documentation. The analysis tools used are IFE Analysis (internal factors evaluation) and EFE (external factor evaluation). The results showed that tea smallholder agro industry of Barokah Farmer Group has a strong internal position where the strengths that have been able to cover the weakness well but have not been able to exploit the opportunities optimally and become very vulnerable to the threat of competition so that tea smallholder agro industry of Barokah Farmer Group is weak in facing the dynamics of the external environment.
\end{abstract}

Keywords: agroindustry, tea smallholder, tea processing unit

DOI: http://dx.doi.org/10.25181/jaip.v6i2.778

Diterima: 18 Maret 2018 / Disetujui: 26 Agustus 2018 / Diterbitkan: 17 Oktober 2018

\section{PENDAHULUAN}

Perkebunan teh rakyat di Indonesia merupakan yang paling luas dibandingkan dengan perkebunan negara dan perkebunan swasta. Berdasarkan Angka Tetap Ditjen Perkebunan Tahun 2014 (Direktorat Jenderal Perkebunan, 2015), terdapat lima kabupaten di Jawa Barat sebagai sentra produksi yaitu Kabupaten Bandung yang merupakan Kabupaten dengan produksi teh terbanyak, kemudian kabupaten Cianjur, Kabupaten Tasik, Kabupaten Garut dan Kabupaten Sukabumi (Kementerian Perindustrian Republik Indonesia, 2013). Dari lima kabupaten tersebut Kabupaten Bandung merupakan kabupaten dengan produktivitas terbesar yaitu 2.501 ton.ha ${ }^{-1}$.

Saat ini di Kecamatan Ciwidey Kabupaten Bandung terdapat beberapa unit pengolahan teh rakyat yang mengalami ketidakstabilan dan akhirnya harus gulung tikar. Hal tersebut disebabkan 
oleh beberapa faktor seperti kekurangan bahan baku, harga pucuk teh yang tidak seimbang, kesalahan manajemen baik di tingkat produksi maupun pemasaranya.

Unit pengolahan teh rakyat Kelompok Tani Barokah yang berdiri sejak tahun 2004 ini merupakan satu-satunya agroindustri teh rakyat yang dapat bertahan saat ini dengan jumlah anggota kelompok tani sebanyak 26 orang. Luas lahan yang mereka kelola yaitu seluas 50 ha, dimana produk olahan teh yang dihasilkanya adalah teh hijau dengan rata-rata hasil produski sebesar 30 ton.bulan ${ }^{-1}$ dan teh putih $20 \mathrm{~kg}$.bulan ${ }^{-1}$. Walaupun hasil produksi pucuk teh yang belum tinggi dan tidak selalu konstan setiap bulanya, Kelompok Tani Barokah ini masih dapat tetap bertahan di tengah persaingan yang ada. Untuk itu dalam penelitian ini dilakukan analisis faktor lingkungan internal dan eksternal yang ada pada agroindustri teh rakyat kelompok tani barokah untuk mengetahui apakah agroindustri teh rakyat ini memiliki kondisi internal yang kuat dan mampu memanfaatkan peluang dengan baik agar memiliki bargaining position ditengah persaingan yang ada.

\section{METODE PENELITIAN}

Penelitian ini dilakukan pada agroindustri teh rakyat berlokasi di Desa Lebak Muncang, Kecamatan Ciwidey, Kabupaten Bandung Provinsi Jawa Barat. Dalam penelitian ini menggunakan desain kualitatif dan teknik penelitian yang digunakan adalah studi kasus.

Data primer diperoleh dengan melakukan wawancara mendalam dan observasi langsung dilapangan. Informan pada penelitian ini dipilih secara purposive yaitu ketua kelompok tani Barokah, General Manager unit pengolahan teh rakyat Kelompok Tani Barokah, staff Desa Lebak Muncang, staff Dinas Perkebunan Provinsi Jawa Barat dan Staff Dinas Perkebunan Kabupaten Bandung.

Penggalian data sekunder juga dilakukan untuk melengkapi data primer, yaitu dengan cara: mengumpulkan dan mempelajari data tertulis berupa dokumen-dokumen atau transkip, koran, jurnal, bulletin, dan membuka akses melalui internet mencari website yang terkait dengan penelitian ini. Apabila data yang diberikan informan belum mencukupi (belum "jenuh") maka untuk melengkapinya dilakukan teknik penelusuran dengan cara snowball sampling.

Data dan informasi yang diperoleh dianalisis dengan menggunakan analisis Analisis Internal Factor Evaluation (IFE) dan External Factor Evaluation (EFE) yang digunakan untuk mengetahui faktor-faktor internal yang berkaitan dengan kekuatan dan kelemahan perusahaan dan faktor eksternal perusahaan berkaitan dengan peluang dan ancaman yang dianggap penting (Ningsih \& Hamamah, 2014). 


\section{HASIL DAN PEMBAHASAN}

Agroindustri teh rakyat Kelompok Tani Barokah terbentuk sebagai sebuah inisiasi guna menyalurkan hasil tani mereka agar tidak menjualnya ke tengkulak. Pabrik yang dikelola oleh kelompok tani barokah ini memiliki masing-masing satu unit mesin pengolahan dengan kapasitas terpasang mesin 7 ton dan kapasitas terpakai sebanyak 5 ton. Saat ini jumlah anggota Kelompok Tani Barokah adalah 26 orang yang dipimpin oleh H. Wildan sebagai ketuanya. Agroindustri teh rakyat Kelompok Tani Barokah memiliki kebun teh seluas 50 ha yang terdiri atas 45 ha komoditas teh hijau dan 5 ha komoditas teh putih. Saat ini, produk teh yang diproduksi oleh agroindustri teh rakyat kelompok tani barokah berupa teh hijau dan teh putih dengan merk Pucuk Sari.

Berdasarkan hasil analisis dengan menggunakan Analisis IFE dan EFE faktor-faktor internal yang berkaitan dengan kekuatan dan kelemahan dan faktor eksternal yang berkaitan dengan peluang dan ancaman yang dianggap penting untuk diperhatikan oleh Agroindustri Teh Rakyat Kelompok Tani Barokah adalah sebagai berikut:

\section{Faktor internal}

Kondisi internal yang terdapat pada unit pengolahan teh rakyat kelompok tani barokah yang meliputi kekuatan dan kelemahan adalah sebagai berikut:

\section{Kekuatan (strength)}

Faktor-faktor internal yang menjadi kekuatan bagi unit pengolahan teh rakyat Kelompok Tani Barokah untuk tetap dapat bertahan diantaranya adalah :

1) Adanya proses sorting dan grading sehingga dihasilakan berbagai jenis olahan teh seperti Gun Powder yang diproduksi sebanyak yaitu 3\% dari total produksi, pecco super $15 \%$ dari total produksi, Chunmee 5\% dari total produksi, Fanning 8\% dari total produksi, Pecco satu 20\% dari total produksi dan keringan $49 \%$ dari total produksi. Komposisi tersebut dinilai sudah pas oleh pihak pabrik karena memberikan margin keuntungan yang paling tinggi. Hal tersebut dilakukan untuk dapat mengikuti permintaan konsumen yang berbeda- beda. Selain itu dengan adannya pengelompokan jenis teh dapat memberikan nilai tambah yang lebih bagi agroindustri ini karena harga jual hasil olahanya lebih beragam.

2) Sudah melakukan pengembangan produk olahan berupa teh putih, dimana saat ini teh putih mnerupakan salah satu teh premium yang memiliki harga jual yang cukup tinggi yaitu Rp1.500.000 per kg.

3) Berbentuk kelompok tani yang memberikan kekuatan tersendiri untuk agroindustri teh rakyat ini dapat terus bertahan karena dengan bentuk yang berupa kelompok tani kegiatan mulai dari on farm hingga off farm menjadi lebih terorganisir.

4) Pekerja yang solid dengan rasa kekeluargaan, hal tersebut sesuai dengan salah satu misi unit pengolahan teh ini yaitu mengedepankan kerjasama dan kekeluargaan seiring dengan kemajuan perusahaan. 
5) Pembayaran bahan baku kepada petani secara tunai sehingga memberikan dampak positif terhadap jalinan kerjasama untuk jangka waktu yang panjang karena dengan pembayaran secara tunai kepada petani akan memberikan kepuasan tersendiri bagi petani pemasok pucuk teh tersebut.

\section{Kelemahan (weakness)}

Faktor internal lain yang dianalisis adalah kelemahan yang terdapat pada unit pengolahan teh rakyat Kelompok Tani Barokah. Kelemahan-kelemahan tersebut diantaranya:

1) Pasokan bahan baku berupa pucuk teh dari petani yang kurang menyebabkan perlu membeli teh keringan teh dari pabrik lain.

2) Kondisi kebersihan pabrik yang belum diperhatikan yang dapat mempengaruhi kehigienisan produk yang dihasilkan.

3) Belum adanya standard operational procedure (SOP) tertulis baik di kebun maupun di pabrik pengolahan. Hal tersebut dibutuhkan untuk membantu menyediakan informasi secara konsisten kepada para pekerja dalam menjalankan setiap kegiatanya.

4) Jaringan pemasaran belum luas yang saat ini distribusi hanya dilakukan kepada para pembungkus (packer) di wilayah Bandung, Cirebon dan Jawa Tengah.

5) Unit pengolahan teh rakyat ini hanya mampu membeli pucuk teh dari petani dengan harga di bawah agroindustri teh lain hal tersebut menimbulkan keresahan para petani yang menjual pucuk teh nya kepada unit pengolahan teh Kelompok Tani Barokah

6) Belum memanfaatkan adanya e-commerce sebagai media penjualan secara online. Dengan memanfaatkan media penjualan secara online baik dengan membuat Blog ataupun membuat akun media sosial untuk sarana penjualan dapat memperluas jaringan pemasaran.

Dari uraian diatas berdasarkan hasil wawancara secara mendalam dengan informan kunci bahwa hal yang saat ini menjadi kekuatan utama unit pengolahan teh rakyat ini masih dapat tetap bertahan adalah adanya proses sorting dan grading sehingga menghasilkan beberapa jenis teh. Sedangkan kelemahan yang paling berpengaruh saat ini adalah kurangnya pasokan bahan baku berupa pucuk teh dari petani sehingga tidak dapat memenuhi target produksi. Untuk mengatasinya dilakukan pembelian teh kering kepada pabrik lain di daerah Sukabumi atau Cianjur.

Total attractive score yang diperoleh adalah 3,22 (Tabel 1). Hal tersebut menunjukan bahwa unit pengolahan teh rakyat Kelompok Tani Barokah memiliki posisi internal yang kuat dimana kekuatan yang dimiliki dapat menutupi kelemahan secara baik. Kekuatan ini akan semakin baik jika diperkuat yaitu salah satu caranya dengan strategi promosi kreatif. Hal ini sesuai pernyataan Rangkuti (2002) dan Farela \& Darma (2014) yang menegaskan bahwa kini telah terjadi perubahan yang signifikan dalam era persaingan global. Media iklan tidak cukup hanya bersifat satu arah, namun harus dua arah yaitu melibatkan target pasar dengan pelbagai bentuk media komunikasi. 
Tabel 1. Hasil analisis menggunakan analisis matrik IFE

\begin{tabular}{llcc}
\hline \multicolumn{1}{c}{ Faktor strategi internal } & Rating & Bobot & Skor \\
\hline Kekuatan & 4 & 0,125 & 0,5 \\
1. $\quad$ Adanya proses sorting dan grading & 4 & 0,125 & 0,5 \\
2. $\quad \begin{array}{l}\text { Melakukan pengembangan produk olahan berupa } \\
\quad \text { teh putih }\end{array}$ & 4 & 0,125 & 0,5 \\
3. $\quad$ Berbentuk kelompok tani & 4 & 0,125 & 0,5 \\
4. $\quad$ Pekerja yang solid dengan rasa kekeluargaan & 4 & 0,125 & 0,5 \\
5. $\quad$ Pembayaran bahan baku kepada petani secara & & & \\
\hline
\end{tabular}

\section{Kelemahan}

1. Kurangnya pasokan pucuk teh dari petani

$2 \quad 0,06 \quad 0,12$

2. Kondisi kebersihan pabrik yang belum diperhatikan

3. Belum adanya SOP tertulis

0,06

0,12

4. Jaringan pemasaran belum luas

$\begin{array}{lll}2 & 0,06 & 0,12 \\ 2 & 0,06 & 0,12\end{array}$

5. Membeli pucuk teh dari petani dengan harga yang lebih rendah dibandingkan pabrik lain

$2 \quad 0,06 \quad 0,12$

6. Belum memanfaatkan adanya e-commerce sebagai media penjualan secara online

\section{Total} 32

0,06

0,12

\section{Faktor eksternal}

Faktor eksternal yang dianalisis adalah berupa peluang dan ancaman yang dianggap penting oleh Agroindustri Teh Rakyat Kelompok Tani Barokah ini.

\section{Peluang (opportunity)}

Hal-hal yang menjadi peluang bagi agroindustri teh rakyat kelompok tani barokah ini untuk dapat berkembang diantaranya adalah:

1) Permintaan konsumen akan teh hijau ataupun teh putih terus meningkat.

Hal tersebut dikarenakan budaya meminum teh menjadi salah satu budaya warga Indonesia. Selain itu saat ini banyak industri makanan dan minuman yang menggunakan teh sebagai salah satu campuran olahanya.

2) Adanya hubungan baik dengan lembaga pemerintah seperti dinas perkebunan Jawa Barat maupun Kabupaten Bandung dalam memfasilitasi untuk kegiatan promosi. Selain itu hubungan baik dengan lembaga pemerintahan terkait, memberikan dampak positif terhadap kemudahan 
memperoleh informasi mengenai program-program bantuan ataupun informasi mengenai penyelengaraan pameran (David, 2009).

3) Adanya permintaan untuk ekspor

Indonesia sebagai salah satu negara produsen teh ke tujuh terbesar di dunia menjadikan negara Indonesia menjadi salah satu negara pilihan untuk mengekspor teh. Hal tersebut menjadi salah satu peluang untuk dapat mengembangkan pasar dengan melakukan ekspor. Berikut data volume ekspor teh dalam kurun waktu 2010-2014 (Tabel 2).

Tabel 2. Perkembangan ekspor teh hijau dari Indonesia tahun 2010- 2014

\begin{tabular}{ccc}
\hline Tahun & Volume (ton) & Nilai US\$ \\
\hline 2010 & 11.403 & 34.781 \\
2011 & 9.525 & 34.315 \\
2012 & 11.607 & 36.767 \\
2013 & 12.138 & 38.062 \\
2014 & 12.135 & 37.495
\end{tabular}

Sumber: Direktorat Jenderal Perkebunan, 2016

Volume ekspor teh hijau tahun 2010-2014 terus mengalami peningkatan sehingga memberikan peluang yang baik untuk melakukan ekspor. Kenaikan volume ekspor diiringi pula dengan meningkatkan nilai jual teh hijau pasar internasional.

4) Masih jarangnya agroindustri teh rakyat di Kecamatan Ciwidey yang melakukan grading dan mengusahakan teh putih.

\section{Ancaman (treath)}

Selain peluang terdapat pula ancaman yang dianggap penting. Ancaman-ancaman tersebut diantaranya adalah:

1) Adanya pesaing-pesaing baru yang dapat menimbulkan persaingan dalam memperoleh pucuk teh maupun persaingan harga jual produk olahan teh.

Persaingan merupakan salah satu hal yang tidak dapat dihindari oleh usaha manapun termasuk Agroindustri Teh Rakyat Kelompok Tani Barokah. Ancaman yang dihadapi oleh agroindustri teh rakyat Kelompok Tani Barokah adalah harga beli pucuk teh dari petani yang lebih tinggi yang ditawarkan oleh agroindustri-agroindustri teh rakyat baru.

2) Adanya masyarakat ekonomi ASEAN dimana produk-produk yang berasal dari luar negara Indonesia akan menguasai pasar lokal termasuk produk teh hijau ataupun teh putih.

3) Agroindustri teh lain berani membeli pucuk teh dengan harga yang lebih tinggi sehinga terjadi persaingan dalam mendapatkan bahan baku berupa pucuk teh dari petani. 
Dari uraian di atas berdasarkan hasil wawancara secara mendalam kepada informan kepada pihak pengelola, hal yang saat ini menjadi peluang besar untuk unit pengolahan teh rakyat ini mampu bertahan adalah permintaan konsumen akan teh hijau maupun teh putih yang terus ada. Tren pasar menunjukkan kecenderungan bahwa kepuasan pelanggan ditentukan oleh kualitas produk. Dengan membaca peluang yang ada, maka pihak pengelola perlu memperhatikan kebutuhan dan keinginan konsumen karena akan berdampak pada loyalitas konsumen pada suatu produk (Kurriwati, 2015). Sedangkan ancaman yang dianggap paling penting saat ini adalah munculnya agroindustri teh rakyat teh baru di wilayah yang sama yang membeli pucuk teh dari petani dengan harga yang lebih tinggi sehingga akan menimbulkan persaingan dalam memperoleh pucuk teh dari petani. Hasil analisis menggunakan analisis matrik EFE disajikan pada Tabel 3.

Tabel 3. Hasil analisis menggunakan analisis matrik EFE

\begin{tabular}{|c|c|c|c|c|}
\hline & Faktor strategi eksternal & Rating & Bobot & Skor \\
\hline \multicolumn{5}{|c|}{ Peluang } \\
\hline 1 & $\begin{array}{l}\text { Permintaan konsumen akan teh hijau ataupun teh putih } \\
\text { tidak akan punah }\end{array}$ & 3 & 0,15 & 0,45 \\
\hline 2 & Adanya permintaan untuk ekspor & 3 & 0,15 & 0,45 \\
\hline 3 & $\begin{array}{l}\text { Adanya hubungan baik dengan lembaga pemerintah } \\
\text { seperti Dinas Perkebunan Jawa Barat maupun Dinas } \\
\text { Perkebunan Kabupaten Bandung }\end{array}$ & 2 & 0,10 & 0,20 \\
\hline 4 & $\begin{array}{l}\text { Masih jarangnya agroindustri teh rakyat di Kecamatan } \\
\text { Ciwidey yang melakukan grading dan mengusahakan teh } \\
\text { putih }\end{array}$ & 3 & 0,15 & 0,45 \\
\hline \multicolumn{5}{|c|}{ Ancaman } \\
\hline 1 & Adanya pesaing - pesaing baru & 3 & 0,15 & 0,45 \\
\hline 2 & Adanya masyarakat ekonomi ASEAN & 3 & 0,15 & 0,45 \\
\hline 3 & $\begin{array}{l}\text { Agroindustri teh lain berani membeli pucuk teh dengan } \\
\text { harga yang lebih tinggi }\end{array}$ & 3 & 0,15 & 0,45 \\
\hline & Total & 20 & $\mathbf{1 , 0 0}$ & 2,90 \\
\hline
\end{tabular}

Total Attractive Score dengan hasil sebesar 2,90. Hal tersebut menunjukkan bahwa agroindustri teh rakyat Kelompok Tani Barokah belum mampu memanfaatkan peluang secara optimal serta menjadi sangat rentan terhadap ancaman persaingan sehingga unit pengolahan teh rakyat ini lemah dalam menghadapi dinamika lingkungan eksternal. Hasil ini selaras dengan hasil penelitian Sitompul et al. (2014) yang menyatakan bahwa perlu upaya perbaikan terutama dengan cara mengoptimalkan koordinasi dengan pihak pemerintah daerah atau dinas terkait 


\section{KESIMPULAN}

Berdasarkan hasil analisis lingkungan internal dan eksternal yang ada maka unit pengolahan teh rakyat Kelompok Tani Barokah memiliki posisi internal yang kuat dimana kekuatan yang dimiliki dapat menutupi kelemahan secara baik namun belum mampu memanfaatkan peluang secara optimal serta menjadi sangat rentan terhadap ancaman persaingan sehingga agroindustri teh rakyat ini lemah dalam menghadapi dinamika lingkungan eksternal. Oleh karena itu unit pengolahan teh rakyat Kelompok Tani Barokah ini perlu membuat strategi yang dapat meningkatkan kekuatan dengan memanfaatkan peluang secara optimal agar unit pengolahan teh rakyat Kelompok Tani Barokahi lebih kuat dalam menghadapi dinamika lingkungan eksternal dengan cara memperluas jaaringan pemasaran dengan penjualan online berbasis community ataupun melakukan kemitraan dengan industri teh celup instan.

\section{DAFTAR PUSTAKA}

David, F. R. (2009). Manajemen Strategis. Edisi Sepuluh. Jakata: Salemba Empat. Jakarta.

Direktorat Jenderal Perkebunan. (2015). Statistik Perkebunan Indonesia Komoditas Teh (20142016). Jakarta: Direktorat Jenderal Perkebunan.

Direktorat Jenderal Perkebunan. (2016). Outlook Teh Komoditas Pertanian Subsektor Perkebunan. Pusat Data dan Sistem Informasi Pertanian Sekretariat Jenderal Kementerian Pertanian. Jakarta.

Farela, D., \& Darma, G. S. (2014). Celebrity endorser, daya tarik iklan, brand awareness dan brand attitude. Jurnal Manajemen dan Bisnis, 11(1), 35-47.

Rangkuti, F. (2013). Strategi Promosi yang Kreatif dan Analisis Kasus. Jakarta: PT Gramedia Pustaka Utama.

Kementerian Perindustrian Republik Indonesia. (2013). Perkembangan Jumlah Unit Usaha Industri Besar dan Sedang Indonesia 2010-2013. Kementerian Perindustrian Republik Indonesia. Jakarta.

Kurriwati, N. (2015). Pengaruh kualitas produk terhadap kepuasan dan dampaknya terhadap loyalitas konsumen. Eco-Entrepreneur, 1(1), 48-55.

Ningsih, K., \& Hamamah, H. (2014). Matriks internal factor evaluation (IFE) dan external factor evaluation (EFE) buah naga organik (Hylocereus undatus). AGROMIX, 5(1), 12-21.

Sitompul, A., Maryunianta, Y., \& Fauzia, L. (2014). Strategi pengembangan agroindustri salak kasus: Desa Parsalakan, Kecamatan Angkola Barat, Kabupaten Tapanuli Selatan. Journal of Agriculture and Agribusiness Socioeconomics, 3(4), 1-14. 